\title{
A PRODUÇÃO CIENTÍFICA DISCENTE EM INDEXAÇÃO E RESUMOS: EM CENA O ENCONTRO NACIONAL DOS ESTUDANTES DE BIBLIOTECONOMIA, DOCUMENTAÇÃO, CIÊNCIA E GESTÃO DA INFORMAÇÃO
}

\author{
SCIENTIFIC PRODUCTION OF STUDENTS ABOUT \\ INDEXING AND ABSTRACTS: IN SCENE THE \\ ENCONTRO NACIONAL DOS ESTUDANTES DE \\ BIBLIOTECONOMIA, DOCUMENTAÇÃO, CIÊNCIA E \\ GESTÃO DA INFORMAÇÃO
}

Adilson Ribeiro de Sá Júniora

Lais Pereira de Oliveirab

\begin{abstract}
RESUMO
Introdução: Analisa a temática indexação e resumos em produções científicas biblioteconômicas discentes. Objetivo: Objetiva constatar a abordagem predominante e os desdobramentos no assunto a partir das pesquisas apresentadas no âmbito do Encontro Nacional dos Estudantes de Biblioteconomia, Documentação, Ciência e Gestão da Informação. Metodologia: Metodologicamente, constitui estudo descritivo de abordagem quali-quantitativa. Caracteriza-se, ainda, como pesquisa bibliográfica nos artigos completos submetidos na modalidade de apresentação oral sobre o tema indexação e resumos. O conjunto prospectado nos anais de 2017 e 2016 foi analisado mediante a técnica de análise de conteúdo. Resultados: Os resultados indicam um maior número de publicações em 2017, boa parte em autoria dupla ou tripla e em grupos de trabalho fora da área de organização e tratamento da informação. Constatou-se também que sobressai a abordagem sobre indexação em detrimento do resumo, não havendo nenhum artigo tratando especificamente sobre o mesmo. Observam-se ainda, desdobramentos diversos para a temática indexação, contemplando discussões em âmbito não tradicional como em documentos audiovisuais e blogs. Conclusões: Conclui-se com a primazia teorizante em indexação na produção científica discente.
\end{abstract}

Descritores: Organização e tratamento da informação. Indexação. Resumo documentário. Produção científica. Encontro de estudantes.

\footnotetext{
a Graduando em Biblioteconomia pela Universidade Federal de Goiás (UFG). E-mail: adilsonribeiro@outlook.com

b Docente do curso de graduação em Biblioteconomia da Universidade Federal de Goiás

(UFG). Doutoranda em Ciência da Informação pela Universidade Estadual Paulista Júlio de Mesquita Filho (Unesp). E-mail: laispereira2@yahoo.com.br
} 


\section{INTRODUÇÃO}

Indexação e resumos está presente em muitos cursos de Biblioteconomia brasileiros como disciplina formalmente estabelecida. É também área aplicada refletida no tratamento temático da informação, sob a qual se debruçam bibliotecários em busca da representação informacional orientada pelo assunto contido nos documentos. Além disso, representa um campo de estudo e investigação que gera pesquisas com os mais diversos enfoques e objetivos.

A indexação é o processo pelo qual o assunto é representado a partir de um termo cuidadosamente selecionado mediante análise conceitual prévia. Caracteriza-se, portanto, como "[...] uma atividade componente do tratamento temático da informação, que representa, por meio de termos ou palavraschave, o conteúdo de um documento" (VIEIRA; OLIVEIRA; CUNHA, 2017, p. 29). Visa, portanto, "[...] a análise e representação de assuntos dos conteúdos documentais" (BOCCATO; FUJITA, 2011, p. 208).

O resumo, por sua vez, é um tipo de representação temática consubstanciada na forma de texto. Nesse sentido, constitui "[...] um meio privilegiado de divulgação e seleção dos documentos primários, nomeadamente no que se refere à literatura científica" (SIMÕES, 2015, p. 33). Em síntese, pode-se dizer que resumos são uma forma condensada de representar informações. Disponibilizados ao usuário durante o processo de busca, dão-Ihe uma prévia do teor do documento, auxiliando no processo de tomada de decisão para seleção da informação que lhe é pertinente.

Lancaster (2004, p. 6) explica que "A indexação de assuntos e a redação de resumos são atividades intimamente relacionadas, pois ambas implicam a preparação de uma representação do conteúdo temático dos documentos". Ademais, indexar e resumir são ações que se dedicam a evidenciar assunto, apenas o produto de cada uma é que será diferente.

Como observam Dal'Evedove e Fujita (2017, não paginado) “[...] diversas questões permeiam a indexação como área de estudo e atividade 
profissional". Com o resumo não é diferente; a ponto de Izquierdo Alonso e Sánchez Domínguez (2011) delimitarem suas dimensões gnosiológica, procedimental e estratégica e, por fim, criativa.

Logo, a compreensão sobre a temática indexação e resumos, orientada pela produção científica no campo, é o foco da presente pesquisa. A problemática foi: qual a abordagem predominante e os desdobramentos no tema indexação e resumos presentes nas pesquisas apresentadas no Encontro Nacional dos Estudantes de Biblioteconomia, Documentação, Ciência e Gestão da Informação?

A investigação norteia-se, assim, por um canal distinto dos que tradicionalmente são objeto de pesquisa teórica, quais sejam os portais de periódicos e as bases de dados especializadas. O foco foi sobre anais de evento, em um fórum discente específico. Objetivou-se constatar a abordagem predominante e os desdobramentos no tema indexação e resumos presentes nas pesquisas apresentadas no Encontro Nacional dos Estudantes de Biblioteconomia, Documentação, Ciência e Gestão da Informação.

Robredo (2005) evidencia que apesar de tão antigas quanto as bibliotecas, a elaboração de resumos e a indexação não mereceram tanta atenção quanto a catalogação. Logo, em termos teóricos a pesquisa pode contribuir com os estudos nesse contexto, explorando uma dimensão fundamental à sua compreensão, qual seja a teórico-conceitual. Em uma perspectiva prática vislumbra-se a contribuição com a vertente aplicada, que se refere ao ato de indexar e elaborar resumos documentários, a partir da ênfase sobre os subtemas que se sobressaem na literatura produzida.

\section{ORGANIZAÇÃO E TRATAMENTO DA INFORMAÇÃO}

A informação produzida cotidianamente demanda formas de organização que permitam acessá-la posteriormente. A capacidade humana de elaborar registros documentais e o aumento significativo sobre essa prática dificultou a identificação e o acesso às informações, gerando a necessidade de produzir informação sobre informação (DIAS; NAVES, 2013). 
Ao produzir informação sobre informação constituem-se representações por meio das quais se reconhece e acessa o conjunto informacional completo presente em um documento. Organização e tratamento da informação (OTI) é justamente o campo que vai propiciar isto. Vale destacar, nessa via, que "[...] para organizar a informação, é preciso descrevê-la, isto é, enumerar as características do objeto ou as relações dele com outros objetos que o identifiquem, o que muitos autores denominam tratamento da informação" (BETTENCOURT, 2014, p. 52).

Pode-se então definir a OTI como a área "[...] que se dedica a investigar e conduzir processos técnicos de ordenação, arranjo e representação informacional" (OLIVEIRA, 2018, p. 247). Sendo que "[...] o tratamento da informação especificamente apresenta diversos processos" (REIS et al., 2018, p. 43) em âmbito descritivo e temático.

A dimensão descritiva contempla o processo de catalogação. Já na dimensão temática tem-se os processos de classificação, indexação e elaboração de resumos documentários. Os dois últimos são o foco da presente investigação, não em sua via aplicada, mas sim, na teórico-conceitual.

\subsection{INDEXAÇÃo}

Indexação é o processo de atribuição de termos para caracterizar um documento pelo assunto. $O$ indexador estabelece uma representação significativa do conteúdo a partir da utilização das palavras-chave que the digam respeito. Lancaster $(2004$, p. 6) observa que "[...] de modo mais evidente, os termos atribuídos pelo indexador servem como pontos de acesso mediante os quais um item é localizado e recuperado, durante uma busca por assunto [...]".

Albuquerque (2017, p. 22), por sua vez, explicita que:

Vista por diferentes concepções, mas mantendo um caminho coerente em relação a seus objetivos, a indexação é um processo que pretende à identificação dos conteúdos dos documentos, tendo como resultado a representação desses conteúdos por meio de conceitos que são extraídos no processo de análise. 
Com isso, "[...] ao representar um recurso informacional através de conceitos, a Indexação dinamiza o seu armazenamento, o que viabiliza a recuperação temática em sistemas de informação" (DAL'EVEDOVE; FUJITA, 2017, não paginado). Nessa mesma direção, Araújo Júnior (2007, p. 23) ressalta que a indexação "[...] é um elemento fundamental para o processo de busca e recuperação da informação". Na verdade:

O processo de indexação, além de ter foco no que é abordado no documento, também deve ser direcionado para a necessidade de informação do usuário, materializada por ele na forma de pergunta. É um processo com duas direções: de um lado os documentos e de outro, as necessidades de informação dos usuários. (SOUSA; FUJITA, 2014, p. 22)

Pode-se concluir, com base nisso, que indexação é uma etapa fundamental no ciclo informacional, uma vez que adequadamente conduzida agrega valor ao documento indexado viabilizando a recuperação do mesmo de maneira mais efetiva. Na condução da indexação, conforme Robredo (2005, p. 9):

[...] identificam-se os conceitos de que trata o documento, expressando-os na terminologia utilizada pelo autor (linguagem natural) ou com ajuda de vocábulos ou termos de significação unívoca ou, ainda, por meio de códigos (linguagens documentárias, descritores, sistemas de classificação, etc.).

Para Mendes e Simões (2002, p. 12) "[...] temos que partir, declarada e frontalmente, da convicção de que indexar é muitas vezes um acto de escolha entre duas ou mais hipóteses válidas". Especialmente porque atribuir assunto não é algo simples. Por ser uma atividade complexa:

É comum encontrarmos na literatura especializada diversas definições, acepções e perspectivas [...]. As diferentes visões teóricas, aliada à natureza subjetiva que envolve a representação documental, tornam o seu ensino mais desafiador. Somado a isso, o resultado da indexação está condicionado ao conhecimento geral e especializado do profissional, além de suas experiências e habilidades técnicas. (DAL'EVEDOVE; FUJITA, 2017, não paginado)

Desse modo, uma relevante tessitura se forma no campo da indexação, norteando o universo técnico-laboral e as próprias ações de ensino e pesquisa na área. 


\subsection{RESUMO DOCUMENTÁRIO}

Resumo é um novo texto constituído a partir de um original, evidenciando suas ideias principais. Para Lancaster (2004, p. 100) "resumo é uma representação sucinta, porém exata, do conteúdo de um documento". Nesse sentido, assume ares de instrumento documentário.

Pode-se também caracterizar o resumo a partir de suas funções. Assim, Izquierdo Alonso e Sánchez Domínguez (2011, p. 220, tradução nossa) explicam que o resumo documentário "[...] é um ato social de comunicação com uma dupla função: meta-representadora e meta-comunicadora". Inclusive porque possibilita um retrato conciso do original, ao mesmo tempo em que comunica sobre seu teor.

Robredo (2005, p. 178) explica que "O termo resumo indica o resultado da ação de resumir, condensar um texto ou matéria, discurso, etc., normalmente mediante identificação e extração dos elementos ou partes mais significativos [...]". De acordo com Izquierdo Alonso e Sánchez Domínguez (2011, p. 210, tradução nossa) "A operação de resumir é tão antiga quanto a necessidade humana de esquematizar e sintetizar o pensamento com a finalidade de assimilá-lo, recordá-lo ou armazená-lo".

Já Oliveira (2018, p. 245) lembra que a estruturação de resumos "[...] reflete uma prática profissional biblioteconômica de representação da informação, mas também uma ação comumente demandada no universo acadêmico, quando da constituição de artigos e trabalhos científicos". Apesar disto, a faceta ora explorada é a do resumo como instrumento de representação, contributo do tratamento temático da informação.

$\mathrm{Na}$ construção do resumo o cuidado deve ser o de constituir um novo texto, não realizar cópias do original resumido. Isso porque "[...] o verdadeiro resumo, ainda que inclua palavras que ocorram no documento, é um texto criado pelo resumidor e não uma transcrição direta do texto do autor" (LANCASTER, 2004, p. 100).

Observado atentamente o aspecto da síntese, o resumo tem muito a contribuir com a busca e recuperação da informação. Afinal, "A elaboração de 
resumos apresenta como produto um texto síntese do original que deve servir como meio de seleção pelos usuários" (ORTEGA, 2009, p. 59). Tanto o resumo documentário quanto a indexação de assunto, aliás:

[...] são o meio através do qual se depura o manancial de informação disponível na Internet, proporcionando, deste modo, aos interessados, não a totalidade da informação que se produz numa determinada área específica, mas apenas aquela que, em última análise, vem preencher a sua necessidade de informação. (LANCASTER; NEWAY, 1982 apud SIMÕES, 2015, p. 32)

\section{O ENCONTRO NACIONAL DOS ESTUDANTES DE BIBLIOTECONOMIA, DOCUMENTAÇÃO, CIÊNCIA E GESTÃO DA INFORMAÇÃO (ENEBD)}

O ENEBD surge a partir da articulação do movimento estudantil dos discentes de Biblioteconomia em 1965, durante o regime militar, inserido em um congresso profissional da área, realizado na cidade de São Paulo cuja temática era: "O Ensino da Biblioteconomia: Organização e Atualização dos Cursos (Currículos, Recursos Audiovisuais, Formação de Professores)", com a participação de 50 pessoas (SOUZA, 2000).

Novamente em São Paulo, ocorreu uma segunda edição em 1972, que foi considerada pelos participantes como a primeira, por ser um encontro dedicado exclusivamente aos estudantes. A temática tratada nesta ocasião foi "Formação Profissional: Cooperação Estudantil; A Biblioteca e Outros Veículos de Divulgação; Mercado de Trabalho". A contagem oficial do evento passou a ser realizada a partir deste encontro (SOUZA, 2000).

Desde então o evento teve várias edições (vide tabela 1 ), cada qual orientada por uma temática específica. A última, a 42a , aconteceu na cidade de Belém do Pará de 21 a 27 de julho de 2019.

Tabela 1 - Edições do ENEBD.

\begin{tabular}{|l|l|l|l|l|l|}
\hline $1^{\underline{a}}$ & 1965 & São Paulo & $22^{\underline{a}}$ & 1999 & São Carlos \\
\hline $1^{\underline{a}}$ & 1972 & São Carlos & $23^{\underline{a}}$ & 2000 & Brasília \\
\hline $2^{2^{\underline{a}}}$ & 1975 & Salvador & $24^{\underline{a}}$ & 2001 & Natal \\
\hline $3^{\underline{a}}$ & 1977 & Fortaleza & $25^{\underline{a}}$ & 2002 & Belo Horizonte \\
\hline $4^{\underline{a}}$ & 1978 & Belém & $26^{\underline{a}}$ & 2003 & Curitiba \\
\hline $5^{\underline{a}}$ & 1980 & João Pessoa & $27^{\underline{a}}$ & 2004 & Recife \\
\hline $6^{\underline{a}}$ & 1982 & Belo Horizonte & $28^{\underline{a}}$ & 2005 & Belém \\
\hline
\end{tabular}

Inf. Inf., Londrina, v. 9, n. 1, p. 163 - 183, jan./jun. 2020.

http://www.uel.br/revistas/informacao/ 


\begin{tabular}{|l|l|l|l|l|l|}
\hline $7^{\underline{a}}$ & 1983 & Salvador & $29^{\underline{a}}$ & 2006 & Salvador \\
\hline $8^{\underline{a}}$ & 1984 & Niterói & $30^{\underline{a}}$ & 2007 & São Carlos \\
\hline $9^{\underline{a}}$ & 1985 & Brasília & $31^{\underline{a}}$ & 2008 & Maceió \\
\hline $10^{\underline{a}}$ & 1986 & Fortaleza & $32^{\underline{a}}$ & 2009 & Rio de Janeiro \\
\hline $11^{\underline{a}}$ & 1988 & Porto Alegre & $33^{\underline{a}}$ & 2010 & João Pessoa \\
\hline $12^{\underline{a}}$ & 1989 & Vitória & $34^{\underline{a}}$ & 2011 & Manaus \\
\hline $13^{\underline{a}}$ & 1990 & Recife & $35^{\underline{a}}$ & 2012 & Belo Horizonte \\
\hline $14^{\underline{a}}$ & 1991 & São Paulo & $36^{\underline{a}}$ & 2013 & Recife \\
\hline $15^{\underline{a}}$ & 1992 & Aracaju & $37^{\underline{a}}$ & 2014 & Brasília \\
\hline $16^{\underline{a}}$ & 1993 & Belém & $38^{\underline{a}}$ & 2015 & São Luís \\
\hline $17^{\underline{a}}$ & 1994 & Fortaleza & $39^{\underline{a}}$ & 2016 & Salvador \\
\hline $18^{\underline{a}}$ & 1995 & Rio de Janeiro & $40^{\underline{a}}$ & 2017 & Goiânia \\
\hline $19^{\underline{a}}$ & 1996 & Belo Horizonte & $41^{\underline{a}}$ & 2018 & Rio de Janeiro \\
\hline $20^{\underline{a}}$ & 1997 & São Luís & $42^{\underline{a}}$ & 2019 & Belém \\
\hline $21^{\underline{a}}$ & 1998 & Florianópolis & & & \\
\hline
\end{tabular}

Fonte: elaborada pelos autores com base em EXNEBD (2005).

A quantidade de edições do ENEBD e, as inúmeras pesquisas por ele difundidas nos diversos grupos de trabalho estruturados em cada uma delas, traduzem-se em especial constructo informacional que precisa ser enxergado sob a ótica das discussões e dos desdobramentos temáticos que têm propiciado. Nessa direção vai a presente investigação.

\section{METODOLOGIA}

A investigação é descritiva de abordagem quali-quantitativa. Caracterizase ainda como pesquisa bibliográfica, envolvendo teor analítico sobre artigos completos dentro da temática indexação e resumos, apresentados na modalidade de comunicação oral e publicados nos anais eletrônicos dos ENEBD's. Os critérios supramencionados foram observados por se considerar a possibilidade de maior desenvolvimento do assunto, que não acontece nos trabalhos de dimensão reduzida, apresentados em pôster.

Em razão da indisponibilidade digital dos anais das 42 edições do evento, optou-se por trabalhar com amostragem priorizando, especificamente, aquelas mais recentemente realizadas. Elegeu-se, assim, recorte analíticocomparativo com vistas a verificar novas temáticas insurgentes em indexação e resumos, razão pela qual o foco foi sobre os últimos cinco ENEBD's.

Apesar da intenção primeva de reunir amplitude amostral comparativa, considerando os último cinco anos, a análise foi feita apenas sobre os 
trabalhos dos ENEBD's de 2017 e 2016, em função da disponibilidade digital desses anais, o que não aconteceu com as edições de 2019, 2018 e 2015, que completariam a margem estabelecida inicialmente. Percebeu-se já na prospecção entre os vários ENEBD's, que há casos nos quais a página principal do evento ainda está acessível, mas sem disponibilidade dos anais; e outros em que nem mesmo esta permanece ativa.

Até agosto de 2019, ocasião na qual se conduziu o levantamento, os anais das duas últimas edições - 2019 e 2018 - não haviam sido lançados; fato curioso por se tratarem dos ENEBD's mais recentes. No caso do evento de 2015, o próprio site foi retirado do ar. Inviabilizou-se, assim, a inclusão destas edições considerando o espectro analítico de cinco anos, como se buscava a princípio, restando somente 2017 e 2016.

Ressalta-se, com isso, a necessidade de organização e gestão dos trabalhos apresentados nos ENEBD's, que representam uma valiosa memória científica estudantil. $\mathrm{O}$ fato de um estudo como o que ora se estabelece não alcançar todas as produções já apresentadas no principal encontro de estudantes do universo biblioteconômico reforça a necessidade de prospecção, arquivamento e disponibilização desses trabalhos para usufruto de todos os agentes da área em questão.

Assim sendo, conduziu-se coleta sobre as duas últimas edições dos ENEBD's - 2017 e 2016 - cujos anais estavam integralmente disponíveis online, em busca de artigos sobre a temática indexação e resumos. Vale ressaltar que o escopo analítico levou em consideração o real pertencimento dos trabalhos completos apresentados oralmente ao tema indexação e resumos. Além disso, a prospecção foi feita não apenas nos grupos de trabalho da área de organização e tratamento da informação, mas sim considerando todos os outros. Até porque se observam submissões voltadas a esse contexto mas direcionadas a outros eixos.

Durante a busca, para não se restringir apenas ao que trazia o título dos trabalhos, também foi estabelecida seleção mediante leitura do resumo e da introdução. A análise dos dados obtidos junto aos artigos prospectados no assunto se fez com base na técnica de análise de conteúdo. 


\section{ANÁLISE E INTERPRETAÇÃO DOS DADOS}

A partir de pesquisa bibliográfica nos anais dos ENEBD's de 2017 e 2016 constatou-se um total de seis trabalhos sobre o tema indexação e resumos. No primeiro caso, foram quatro publicações em um universo de 38 apresentadas; no segundo, foram duas em um conjunto de 41 .

Evidencia-se, já de início, a perspectiva trazida por Robredo (2005) acerca da pequena atenção recebida pelas atividades de indexação e resumo. Apesar de positivo o fato de haver trabalhos sobre as temáticas, seria interessante que fossem em maior quantidade, considerando a íntima relação entre elas (LANCASTER, 2004) e a própria amplitude de que dispõem enquanto disciplina formal nos cursos de Biblioteconomia.

O gráfico abaixo expõe o quantitativo de trabalhos por ano, considerando a distribuição por grupos de trabalho:

Gráfico 1 - Quantidade de trabalhos sobre indexação e resumos.

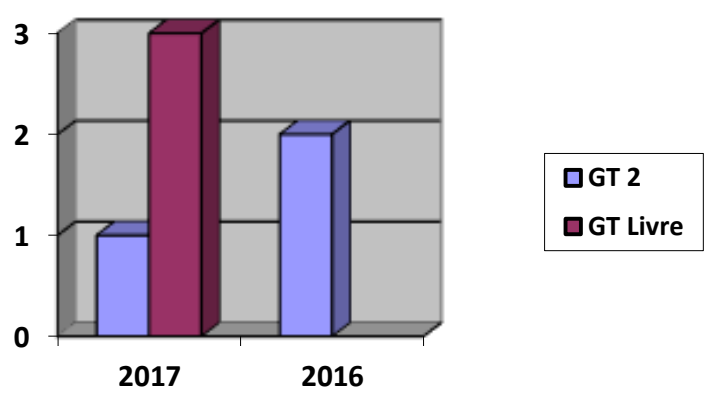

Fonte: elaborado pelos autores (2019).

Como se observa no gráfico 1, em 2017 houve um trabalho em indexação e resumos publicado no GT 2 do evento, denominado Tecnologia da Informação e Comunicação e, três no GT Livre. Além destes dois a referida edição do ENEBD contou com o GT 1 - Organização e Representação da Informação e o GT 3 - Profissionais da Informação: Educar para a Diversidade, nos quais não foram encontrados artigos no assunto.

No ano de 2016 foram dois trabalhos em indexação e resumos, ambos no GT 2 do encontro, nomeado como Gestão e Organização das Bibliotecas. Houve além deste o GT 1 - Informação como Objeto de Estudo das Ciências 
da Informação e como Recurso para o Desenvolvimento Econômico e Social, o GT 3 - O Profissional da Informação e, o GT Livre, sem publicações no tema.

A tabela a seguir delimita os títulos das produções sobre indexação e resumos e os respectivos grupos de trabalho aos quais foram submetidas:

Tabela 2 - Trabalhos sobre indexação e resumos por grupos de trabalho.

\begin{tabular}{|c|c|c|}
\hline \multirow{4}{*}{$\begin{array}{l}\text { XL ENEBD } \\
(2017)\end{array}$} & $\begin{array}{l}\text { GT } 2 \text { - Tecnologia } \\
\text { da Informação e } \\
\text { Comunicação }\end{array}$ & $\begin{array}{l}\text { O uso subjetivo da folksonomia no ambiente } \\
\text { tecnológico: tags, usuários e seus conceitos }\end{array}$ \\
\hline & \multirow{3}{*}{ GT Livre } & $\begin{array}{l}\text { Indexação de documentos audiovisuais: } \\
\text { delineamento teórico do tema em artigos de } \\
\text { periódicos }\end{array}$ \\
\hline & & $\begin{array}{l}\text { Organização da informação digital: estudo da } \\
\text { indexação de conteúdos em blogs de } \\
\text { bibliotecários }\end{array}$ \\
\hline & & $\begin{array}{l}\text { Os gêneros cinematográficos: análise e } \\
\text { conceituação para bases de dados }\end{array}$ \\
\hline \multirow{2}{*}{$\begin{array}{l}\text { XXXIX ENEBD } \\
(2016)\end{array}$} & \multirow{2}{*}{$\begin{array}{l}\text { GT } 2-\text { Gestão e } \\
\text { Organização das } \\
\text { Bibliotecas }\end{array}$} & $\begin{array}{l}\text { Constituição dos estudos sobre política de } \\
\text { indexação: prospecção e análise em } \\
\text { publicações nacionais }\end{array}$ \\
\hline & & $\begin{array}{l}\text { Elaboração de índices para obras de } \\
\text { referência: aplicação na Bibliografia Filatélica } \\
\text { Brasileira (BIFIBRA) }\end{array}$ \\
\hline
\end{tabular}

Fonte: elaborada pelos autores (2019).

Como se constata na tabela 2, o ENEBD demonstra não possuir grupos de trabalho fixos. Assim, a nomenclatura se altera, como aconteceu com o GT 2. Este passou do enfoque na gestão para a ênfase na tecnologia. Além disso, a ampliação ou redução de grupos de trabalho e mesmo a modificação nas ementas a cada nova edição, fazem com que os trabalhos sejam agrupados ou divididos em torno de outros temas. Aspecto esse que dificulta a asserção de uma identidade temática padrão do evento, o que indiretamente é inconsistente para o próprio tratamento temático dos ENEBD's.

Para além dos aspectos técnicos inerentes à organização do evento deve-se ressaltar que, apesar de indexação e resumos ser uma temática inerente à área de organização e tratamento da informação, nenhum dos textos nesse âmbito foi direcionado a tal grupo de trabalho - que no caso de 2017 foi o GT 1 e em 2016, simplesmente não existiu. Uma das razões pode ser o fato de tais processos técnicos permearem aspectos tecnológicos e gerenciais, levando a tal associação pelo discente que submete seu trabalho no ENEBD. 
Pode refletir ainda, o julgamento dos autores da não adequação do texto à ementa posta para o grupo de trabalho voltado à área de organização, encaminhando-o a um eixo livre por essa razão.

Ademais, considerando a importância das atividades de indexação e resumos, que resultam em pontos de acesso e em uma representação textual suscinta (LANCASTER, 2004), é importante refletir sobre o caráter de pesquisa que as mesmas têm assumido. Essencialmente em um contexto discente que congrega a exposição de estudos de alunos em formação. $O$ padrão na tematização dos trabalhos e nos aspectos correlatos associados dizem muito acerca do esclarecimento, da percepção e da ação científica aplicada dos discentes.

Já em relação à autoria, predominam nas duas edições do ENEBD analisadas os trabalhos em co-autoria, com dois ou três autores cada. Assim:

Gráfico 2 - Autoria dos trabalhos em indexação e resumos.

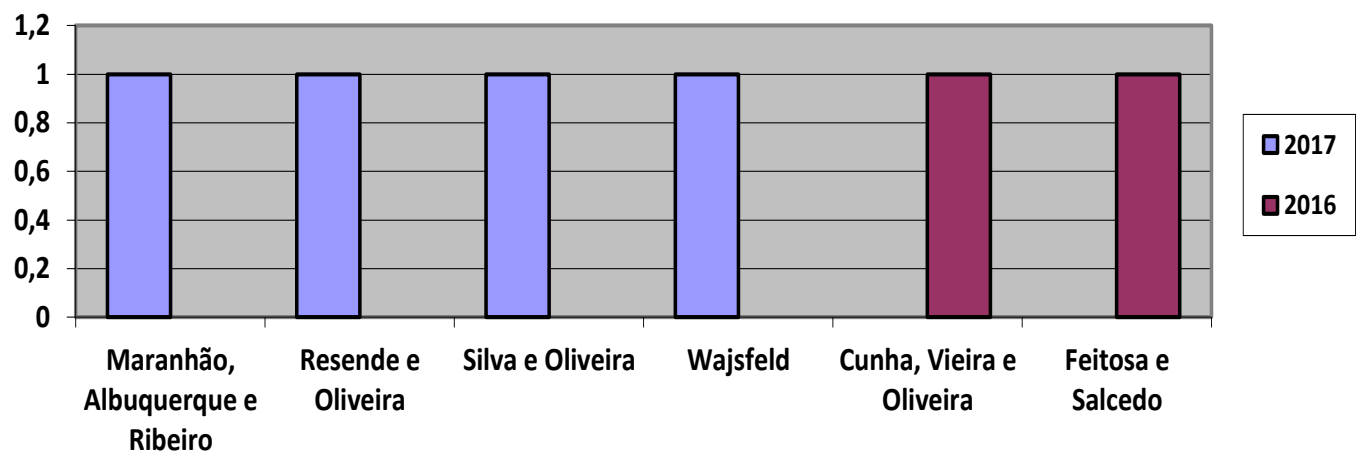

Fonte: elaborado pelos autores (2019).

Nota-se que são três os trabalhos com autoria dupla - dois deles em 2017 - e, dois com autoria tripla - um em cada edição do evento. Apenas um trabalho é em autoria única. Os dados indicam, desse modo, uma tendência à produção colaborativa em indexação e resumos, no caso dos ENEBD's analisados. Essa publicação conjunta pode ser reflexo do trabalho integrado entre orientador e orientando.

A autora com maior número de trabalhos sobre indexação e resumos nos ENEBD's de 2017 e 2016 - todos em co-autoria - é Oliveira; no primeiro caso com duas produções e, no segundo, com apenas uma. Cenário esse que demonstra certa sequência investigativa sobre tais atividades técnicas. Todos 
os demais autores surgem cada qual em apenas uma publicação.

Entretanto, é importante o desdobramento dessa dimensão autoral a partir de investigações sobre as outras edições do evento estudantil, tão logo seja possível o acesso aos anais. Isso pode demonstrar outros pesquisadores que têm permeado o ENEBD com pesquisas em indexação e resumos ao longo do tempo, tanto quanto as parcerias estabelecidas. A sequência em pesquisa de um dado pesquisador também é outra dimensão capaz de ser enxergada, ajudando a caracterizar o desenvolvimento do ato de indexar e resumir em termos teóricos.

No que diz respeito à abordagem presente nos trabalhos, constatou-se o predomínio de produções no tema indexação (vide gráfico 3), que são em número de três. Não foi encontrado nenhum trabalho sobre resumo documentário, individualmente, assim como qualquer estudo que o trouxesse integrado à temática de indexação.

Aparecem ainda, em termos de abordagem temática, variações do assunto indexação. São elas: indexação social, política de indexação e elaboração de índices, cada qual abordada em um artigo.

\section{Gráfico 3 - Abordagem dos trabalhos em indexação e resumos.}

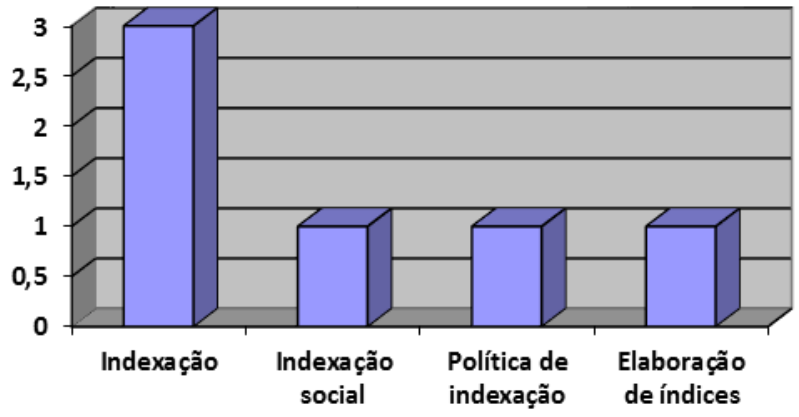

Fonte: elaborado pelos autores (2019).

Essa abordagem unificada demonstra uma percepção processual técnica da OTI restrita a essa ação de indexação, ainda que o tratamento da informação congregue vários processos (REIS et al., 2018). Apesar de fundamental na busca e recuperação (ARAÚJO JÚNIOR, 2007), a indexação não pode ser a única atividade abarcada nas pesquisas discentes. $O$ resumo tem muito a lhe complementar. 
Ao mesmo tempo, tal constatação na investigação denota que o resumo precisa ser mais explorado na formação biblioteconômica até para figurar de modo ativo nos estudos apresentados no ENEBD. Inclusive porque tem uma dimensão gnosiológica (IZQUIERDO ALONSO; SÁNCHEZ DOMÍNGUEZ, 2011) e essa precisa ser desenvolvida e incentivada desde a graduação.

Analisando detidamente cada texto foi possível perceber, ainda, desdobramentos no tema central abordado, descrito no Gráfico 3. Desse modo, tem-se:

\section{Quadro 1 - Desdobramentos dos trabalhos em indexação e resumos.}

\begin{tabular}{|c|c|c|c|}
\hline Edições & Artigo & Abordagem & Desdobramento \\
\hline \multirow{4}{*}{$\begin{array}{c}\text { XL } \\
\text { ENEBD }\end{array}$} & $\begin{array}{l}\text { Indexação de documentos } \\
\text { audiovisuais: delineamento teórico do } \\
\text { tema em artigos de periódicos }\end{array}$ & Indexação & $\begin{array}{l}\text { Documento } \\
\text { audiovisual }\end{array}$ \\
\hline & $\begin{array}{l}\text { Organização da informação digital: } \\
\text { estudo da indexação de conteúdos } \\
\text { em blogs de bibliotecários }\end{array}$ & Indexação & Blogs \\
\hline & $\begin{array}{l}\text { Os gêneros cinematográficos: análise } \\
\text { e conceituação para bases de dados }\end{array}$ & Indexação & $\begin{array}{c}\text { Acervos } \\
\text { cinematográficos }\end{array}$ \\
\hline & $\begin{array}{l}\text { O uso subjetivo da folksonomia no } \\
\text { ambiente tecnológico: tags, usuários } \\
\text { e seus conceitos }\end{array}$ & $\begin{array}{l}\text { Indexação } \\
\text { social }\end{array}$ & Folksonomia \\
\hline \multirow{2}{*}{$\begin{array}{l}\text { XXXIX } \\
\text { ENEBD }\end{array}$} & $\begin{array}{l}\text { Constituição dos estudos sobre } \\
\text { política de indexação: prospecção e } \\
\text { análise em publicações nacionais }\end{array}$ & $\begin{array}{l}\text { Política de } \\
\text { indexação }\end{array}$ & $\begin{array}{l}\text { Publicações em } \\
\text { periódicos }\end{array}$ \\
\hline & $\begin{array}{l}\text { Elaboração de índices para obras de } \\
\text { referência: aplicação na Bibliografia } \\
\text { Filatélica Brasileira (BIFIBRA) }\end{array}$ & $\begin{array}{l}\text { Elaboração } \\
\text { de índices }\end{array}$ & $\begin{array}{l}\text { Obras de } \\
\text { referência }\end{array}$ \\
\hline
\end{tabular}

Fonte: elaborado pelos autores (2019).

Como se observa no quadro acima, os trabalhos do ENEBD que versam sobre o processo de indexação o discutem em um âmbito não tradicional. Isto é, pensam o ato de indexar sobre documentos audiovisuais; digitais, no caso dos blogs; e, em acervos cinematográficos. Demonstra-se com isso um olhar dinâmico sobre a indexação, não mais detido a acervos bibliográficos, somente. Esta vem sendo pensada para atender aos mais diversos contextos. 
Esse alcance da indexação é visto também com o trabalho sobre indexação social, amparado nas folksonomias. Essa perspectiva se mostra importante para pensar, da mesma forma que os anteriores, novas prerrogativas de organização pelo ato de indexar em âmbitos diversos.

A formalização da ação de indexar se mostra a partir do trabalho sobre política de indexação. Nesse ponto evidencia-se, ainda, a preocupação de compreender 0 alcance desse tema, ao observar as publicações feitas sobre 0 mesmo em periódicos.

Por fim, tem-se um trabalho sobre abordagem mais tradicional em indexação, que diz respeito à elaboração de índices. O foco é nas obras de referência. Tem-se, assim, prerrogativa para direcionamento das buscas e localização desse tipo de material.

Em uma perspectiva qualitativa mais abrangente, percebem-se os seguintes enfoques:

- Indexação de documentos audiovisuais: delineamento teórico do tema em artigos de periódicos - 2017

Apresenta um levantamento de publicações em periódicos sobre o tema, analisando principalmente $\mathrm{o}$ aporte teórico utilizado em cada um deles. $O$ estudo tem um caráter exploratório-descritivo, de tipo bibliográfico e com abordagem quanti-qualitativa. O recorte de tempo abrange o período de 45 anos (1972-2017), no qual foram encontrados sete artigos (todos posteriores a 2010), em seis revistas diferentes. Como resultado, aponta-se que mesmo tratando-se de indexação de documentação audiovisual, esse não é o tema central das publicações, mas sim, assunto correlato.

\section{- O uso subjetivo da folksonomia no ambiente tecnológico: tags,} usuários e seus conceitos - 2017

Apresenta uma discussão teórica acerca da folksonomia e, a partir desse aporte teórico, apontas as vantagens e desvantagens desse tipo de estrutura no processo de indexação. $O$ estudo ainda aplica uma pesquisa com estudantes de diversos cursos da Universidade Federal de Pernambuco, a fim de averiguar seus conhecimentos sobre o tema e a utilização de hashtags em 
redes sociais. Como resultado, é apontado em 1ำ lugar o baixo índice de publicações em português sobre 0 assunto e, em $2^{\text {a }}$ lugar que, mesmo praticando a folksonomia diariamente em redes sociais, os usuários desconhecem do que se trata.

- Organização da informação digital: estudo da indexação de conteúdos em blogs de bibliotecários - 2017

Apresenta um levantamento de blogs de bibliotecários e a forma de indexação utilizada para auxiliar no processo de recuperação das informações presentes no conteúdo vinculado a estas plataformas. $O$ estudo tem um caráter exploratório-descritivo, com abordagem quantitativa. Um total de 13 bibliotecários, idealizadores de blogs, foram alvos da pesquisa, que aponta que a formação dos proprietários influenciou diretamente na criação do blog, do conteúdo e da forma de indexar. Além do mais, constatou-se que a forma de indexar utilizada, não difere da tradicionalmente desenvolvida em unidades de informação.

- Os gêneros cinematográficos: análise e conceituação para bases de dados -2017

Apresenta o cinema como um meio de comunicação e de se obter informações e defende a análise dos filmes (como primeira forma de contato com o usuário) através do gênero. $O$ artigo ainda traz uma discussão teórica sobre a trajetória do cinema e seus gêneros, bem como a necessidade de indexação para acervos cinematográficos. Como conclusão o autor sugere que sejam realizados mais estudos aprofundados sobre o tema.

- Constituição dos estudos sobre política de indexação: prospecção e análise em publicações nacionais - 2016

Apresenta a análise sobre as publicações que versam sobre políticas de indexação nas revistas brasileiras de Ciência da Informação, através de revisão bibliográfica. $O$ estudo tem uma abordagem qualitativa, haja vista que foi analisado o conteúdo das publicações. Em um recorte de tempo que abrange de 1998 a 2015, foram localizados 11 periódicos e, nestes estavam 17 artigos, 
sendo 12 de natureza aplicada e cinco de literatura e correntes sobre indexação. $\mathrm{O}$ trabalho conclui que tem aumentado a discussão do tema, que gira em torno do cotidiano do indexador e de estudos de caso em bibliotecas e bases de dados.

- Elaboração de índices para obras de referência: aplicação na Bibliografia Filatélica Brasileira (BIFIBRA) - 2016

Apresenta o relato de caso de um grupo de trabalho responsável pela elaboração de índices para a obra de referência "Bibliofilatelia: fontes de informação para o estudo filatélico e postal". O estudo tem uma abordagem exploratória e descritiva. A pesquisa discute sobre fontes de informação e obras de referência e o papel do bibliotecário na construção de índices, apresentando como resultado a construção de três índices: onomástico, cronológico e por assunto.

Em linhas mais gerais, os trabalhos encontrados nos ENEBD's de 2017 e 2016 têm desdobramentos diferentes em indexação, majoritariamente de ordem teórica. Contudo, sejam eles levantamento de artigos caracterizando discussões teóricas, sejam relatos ou estudos de caso, apontam para a necessidade e importância da indexação em suas mais variadas vertentes.

\section{CONCLUSÃO}

As práticas de indexação e elaboração de resumos constituem importantes etapas no processo de organização e tratamento da informação, caracterizando-se como parte essencial para recuperação da informação. Dada a relevância, a disciplina de indexação e resumos é comum aos currículos dos cursos de Biblioteconomia no Brasil, incitando também o desenvolvimento de pesquisas, inclusive pelos discentes.

Diante disso, a pesquisa buscou constatar a abordagem predominante e os desdobramentos no tema indexação e resumos a partir das pesquisas apresentadas no âmbito das edições do Encontro Nacional dos Estudantes de Biblioteconomia, Documentação, Ciência e Gestão da Informação. Percebeu- 
se o predomínio de trabalhos sobre indexação estendendo-se a diversos subtópicos, evidenciando a exploração do assunto em contextos não tradicionais. Sinaliza-se, com isso, para uma real preocupação de se pensar o ato de indexar para além do tradicional universo bibliográfico-documental no âmbito de relevante fórum científico discente como o ENEBD.

Os dados levantados apontam ainda, para uma produção de destaque em 2017, em autoria dupla ou tripla, orientada para grupos de trabalho fora da área de organização e tratamento da informação. Aspectos esses que ajudam a compreender a configuração assumida pelas pesquisas inclusive em seu aspecto formal de planejamento e submissão.

Estudos futuros podem se dedicar a entender as razões para a submissão de trabalhos sobre indexação e resumos em grupos de trabalho de outra ordem que não organização e tratamento da informação. Outra possibilidade é a exploração dos aspectos de autoria, considerando a própria parceria entre alunos e professores na submissão de trabalhos desse âmbito ao ENEBD, tanto quanto os atores da pesquisa em indexação e resumos mais significativos ao longo dos anos em que foi promovido. Sugere-se também a investigação sobre outras edições do evento, como forma de perceber a amplitude de desdobramentos em indexação em outros momentos, tanto quanto a possível presença de trabalhos sobre resumo.

\section{REFERÊNCIAS}

ALBUQUERQUE, Ana Cristina de. A perspectiva da análise de domínio como aporte à análise de documentos fotográficos: algumas considerações. In: ALBUQUERQUE, Ana Cristina de; SIMIONATO, Ana Carolina (orgs.).

Recursos audiovisuais: sua contemporaneidade na organização e representação da informação e do conhecimento. Rio de Janeiro: Interciência, 2017. p. 13-37.

ARAÚJO JÚNIOR, Rogério Henrique de. Precisão no processo de busca e recuperação da informação. Brasília: Thesaurus, 2007.

BETTENCOURT, Angela Monteiro. A representação da informação na

Biblioteca Nacional: do documento tradicional ao digital. Rio de Janeiro: Fundação Biblioteca Nacional, 2014. 
BOCCATO, Vera Regina Casari; FUJITA, Mariângela Spotti Lopes. A indexação nas perspectivas das concepções de análise de assunto em Bibliotecas Universitárias. Revista EDICIC, v. 1, n. 4, p. 208-220, out./dez. 2011.

DAL'EVEDOVE, Paula Regina; FUJITA, Mariângela Spotti Lopes. Formação do bibliotecário indexador no Brasil: análise dos aspectos temáticos em planos de ensino. In: ENCONTRO DE REPRESENTAÇÃO DOCUMENTAL, 1., 2017, São Carlos. Anais [...]. São Carlos: UFSCAR, 2017.

DIAS, Eduardo Wense; NAVES, Madalena Martins Lopes. Análise de assunto: teoria e prática. 2. ed. rev. Brasília: Briquet de Lemos, 2013.

EXNEBD. Histórico dos ENEBD'S. Recife: EXNEBD, 2005. Disponível em: http://www.eca.usp.br/alunos/associ/cabi/exnebd/historico.html. Acesso em: 05 set. 2019.

IZQUIERDO ALONSO, Mónica; SÁNCHEZ DOMÍNGUEZ, Carmen. Los estudios de resumen documental em las ciencias de la documentación: un recorrido histórico desde sus orígenes hasta las teorias actuales. Revista de Linguística y Lenguas Aplicadas, v. 6, p. 209-228, out. 2011.

LANCASTER, Frederick Wilfrid. Indexação e resumos: teoria e prática. 2. ed. rev. atual. Brasília: Briquet de Lemos, 2004.

MENDES, Maria Teresa Pinto; SIMÕES, Maria da Graça. Indexação por assuntos: princípios gerais e normas. Lisboa: Gabinete de Estudos A\&B, 2002.

OLIVEIRA, Lais Pereira de. Análise das publicações na área de organização e tratamento da informação à luz dos resumos. Revista ACB: Biblioteconomia em Santa Catarina, Florianópolis, v. 23, n. 2, p. 245-266, abr.jjul. 2018.

ORTEGA, Cristina Dotta. Os registros de informação dos sistemas documentários: uma discussão no âmbito da Representação Descritiva. 2009. 250 f. Tese (Doutorado em Ciência da Informação) - Escola de Comunicações e Artes, Universidade de São Paulo, 2009.

REIS, Daniela Majorie Akama dos; FUJITA, Mariângela Spotti Lopes; SANTOS, Plácida Leopoldina Ventura Amorim da Costa; ZAFALON, Zaira Regina.

Tratamento descritivo e temático da informação: recomendações para estudos sobre aspectos semióticos na criação de registros bibliográficos. Revista Ibero-Americana de Ciência da Informação, Brasília, v. 11, n. 1, p. 42-58, jan./abr. 2018.

ROBREDO, Jaime. Documentação de hoje e de amanhã: uma abordagem revisitada e contemporânea da Ciência da Informação e de suas aplicações biblioteconômicas, documentárias, arquivísticas e museológicas. 4. ed. rev. ampl. Brasília: Edição de autor, 2005. 
SIMÕES, Maria da Graça Melo. Resumo documental e literatura científica: origem, desenvolvimento e consolidação. Páginas A\&B, v. 3, n. 3, p. 15-36, 2015.

SOUSA, Brisa Pozzi de; FUJITA, Mariângela Spotti Lopes. Análise de assunto no processo de indexação: um percurso entre teoria e norma. Informação \& Sociedade: Estudos, João Pessoa, v. 24, n. 1, p. 19-34, jan./abr. 2014.

SOUZA, Júlio Farias de. O movimento estudantil e a formação de uma liderança nacional em Biblioteconomia: a contribuição dos Encontros Nacionais de Estudantes de Biblioteconomia e Documentação (ENEBD'S). 2000. 79 f. Monografia (Bacharelado) - Curso de Biblioteconomia, Universidade Federal da Paraíba, João Pessoa, 2000.

VIEIRA, Ana Paula da Fonseca; OLIVEIRA, Lais Pereira de; CUNHA, Tatielle Marques. Incursões sobre o tratamento temático da informação: estudo da política de indexação em bibliotecas universitárias goianas. Informação em Pauta, Fortaleza, v. 2, n. 1, p. 28-49, jan./jun. 2017.

\title{
SCIENTIFIC PRODUCTION OF STUDENTS ABOUT INDEXING AND ABSTRACTS: IN SCENE THE ENCONTRO NACIONAL DOS ESTUDANTES DE BIBLIOTECONOMIA, DOCUMENTAÇÃO, CIÊNCIA E GESTÃO DA INFORMAÇÃO
}

\begin{abstract}
Introduction: It analyzes the indexing and abstracts in student biblioteconomic scientific productions. Objective: It aims to verify the predominant approach and the developments in the subject from the research presented in the scope of the Encontro Nacional dos Estudantes de Biblioteconomia, Documentação, Ciência e Gestão da Informação. Methodology: It is a descriptive research with a qualitative and quantitative approach. It is also characterized as bibliographic research developed from the complete articles published in proceedings and with mode of oral presentation, about the indexing and abstracts. The set prospected in the proceedings of 2017 and 2016 was analyzed using the content analysis technique. Results: The results indicate a greater number of publications in 2017 , mostly in double or triple authorship and in working groups outside the area of information organization and processing. There are a bigger approach about indexing to the detriment of the abstract, about which there is no specific article. There are also several developments in the indexing theme, including discussions in non-traditional scope such as audiovisual documents and blogs. Conclusions: It is concluded with a theorizing primacy in indexing in the student scientific production.
\end{abstract}

Descriptors: Information organization and processing. Indexing. Documentary abstract. Scientific production. Student meeting. 


\title{
PRODUCCIÓN CIENTÍFICA ESTUDIANTIL EN INDIZACIÓN Y RESUMEN: EN LA ESCENA EL ENCONTRO NACIONAL DOS ESTUDANTES DE BIBLIOTECONOMIA, DOCUMENTAÇÃO, CIÊNCIA E GESTÃO DA INFORMAÇÃO
}

\begin{abstract}
RESUMEN
Introducción: Analiza la indización temática y los resúmenes en las producciones científicas biblioteconómicas de los estudiantes. Objetivo: Su objetivo es verificar el enfoque predominante y los desarrollos en el tema a partir de la investigación presentada en el Encontro Nacional dos Estudantes de Biblioteconomia, Documentação, Ciência e Gestão da Informação. Metodología: Metodológicamente, es un estudio descriptivo de enfoque cualitativo y cuantitativo. También se caracteriza por la investigación bibliográfica en los artículos completos presentados en la modalidad de presentación oral sobre la indización y resúmenes de los temas. El conjunto prospectado en los anales de 2017 y 2016 se analizó utilizando la técnica de análisis de contenido. Resultados: Los resultados indican un mayor número de publicaciones en 2017, principalmente en doble o triple autoría y en grupos de trabajo fuera del área de organización y procesamiento de la información. También se encontró que el enfoque de indización sobre el resumen se destaca, y no hay ningún artículo que trate específicamente sobre él. También hay varios desarrollos en el tema de indización, incluidas las discusiones en un ámbito no tradicional, como documentos audiovisuales y blogs. Conclusiones: Concluye con la teoría de la primacía en la indización en la producción científica de los estudiantes.
\end{abstract}

Descriptores: Organización y procesamiento de información. Indización. Resumen documental. Producción científica. Reunión de estudiantes.

Recebido em: 12/09/2019

Aceito em: 14/04/2020 